\title{
Trade, Pollution Transfers and Spillovers: Conditions for Welfare Outcomes
}

\author{
John Dogbey \\ Department of Economics, University of Nebraska at Omaha, Omaha, USA \\ Email: jdogbey@unomaha.edu
}

Received December 1, 2013; revised January 1, 2014; accepted January 8, 2014

Copyright (C) 2014 John Dogbey. This is an open access article distributed under the Creative Commons Attribution License, which permits unrestricted use, distribution, and reproduction in any medium, provided the original work is properly cited. In accordance of the Creative Commons Attribution License all Copyrights (C) 2014 are reserved for SCIRP and the owner of the intellectual property John Dogbey. All Copyright (C) 2014 are guarded by law and by SCIRP as a guardian.

\section{ABSTRACT}

I use a model of indirect utility and compensated demand functions to analyze conditions for welfare effects when countries engage in trade involving a pollutant. The paper questions whether there is a transfer problem in such a trade and what conditions could set the stage for welfare effects. The results show that, countries' (both trade partner's and non-participants') welfares increase not necessarily with distance from the pollution generating location (country) but with their marginal propensities to consume the good, substitutability in the good in question, the type of good (normal, Giffen and or inferior) and the spatial separability of the pollutant.

\section{KEYWORDS}

\section{Welfare Effects; Spatially Separable; Trade; Substitutability; Pollutant; Transfers}

\section{Introduction}

There is a plethora of literature on the relationship between trade and the environment. While few focus on the conditions that determine welfare effects, the debate on whether trade policies affect the environment or whether environmental policies affect trade is widespread. A popular view held by researchers is that trade liberalization can cause an increased specialization in sectors that generate little pollution. A similar consensus among researchers regarding the environment and economic growth is that when a country pursues trade liberalization, it results in economic growth, which in turn reduces pollution. However, stricter environmental policies reduce economic growth and gives rise to a U-Shaped Environmental Kutznets Curve. Researchers find that the nature of a pollutant is important in determining the level of income at which households reduce their exposure to that pollutant. They find that pollutants that are spatially separable (such as $\mathrm{SO}_{2}$ and PM10) affect household pollution exposure decisions at certain income thresholds while goods that are non-spatially separable (such as $\mathrm{CO}_{3}$, $\mathrm{O}_{3}$ and $\mathrm{NO}_{\mathrm{x}}$ ) do not. Grossman and Krueger [1,2]; Huang and Labys [3]; McConnell [4]; Khanna [5]; Khanna and
Plassmann [6].

Most researchers empirically investigate the relationship between environmental pollution and growth or trade and some also use a theoretical framework. Das and Das [7] develop a North-South model of trade in a monopolistic competition market structure. They find that direct effects of welfare arise from abatement policies of the North, whereas the indirect effects are from the effect on wages, prices, varieties and outputs of the policies. The indirect welfare effects depend also on the South trade orientation, elasticity of substitution, dependency ratios and the elasticity of demand.

Heal [8]constructs both a general equilibrium framework and a partial equilibrium framework to calculate the relative weights (discount rates) to be placed on welfare levels taking place at different periods. The premise which used to do so requires information about substitut abilities, preferences and complementarities between environmental stocks, other goods and movements in an economy. They view policies constructed to mitigate greenhouse gas emissions in an industry, for example, in a general equilibrium framework. They conclude that a policy that reduces future consumption will make an economy worse off at the day it occurs but can also make 
the economy better off at a future date by increasing output and consumption.

Similarly, Weitzman [9] also conducts a survey to find the appropriate discount rate for long-term environmental problems like global warming. Copeland and Taylor [10] also develop general equilibrium pollution and trade model using a special case of a canonical pollution haven model and the standard Heckscher-Ohlin-Samuelson factor endowment model. Their model involves a pollution demand and supply system that explains marginal damage and abatement cost schedules.

Copeland and Taylor [11] employ a North-South model of two countries with different pollution intensities and a continuum of goods to show the relationship between international trade, pollution and income. They find that while unilateral transfers from the North to the South as well as an increase in the poor South's production possibilities reduces world pollution; an increase in the rich North's production possibilities increases world pollution.

This study focuses on the welfare effects of trade on environmental quality of countries that engage in trade and their surrounding world. It poses the question under which conditions do countries realize environmental quality gains or losses during trade, whether this gains or losses increase with increasing trade, and whether it is the developed or developing country that is better off. It also addresses whether other countries have any welfare effects as a result of their neighbor's trading activities, especially trade in pollutants. The rest of this paper is organized as follows: in the next section, I present the models and analyze the results, followed by the conclusion and policy recommendations in the final section.

\section{The Model}

\subsection{The General Model}

This paper develops a framework that employs compensated demand functions, indirect utility functions and the overspending functions of countries to analyze welfare effects of bilateral trade in a pollutant in a multilateral context. Modeling a three-country world: $\alpha, \gamma, \beta$, namely the developed country, the developing country and the non-participant(the developed country's aim is to transfer pollution, so it can only engage intrade with a developing country that is not its neighbor) respectively and a two-good world: good $X$ and good $Y$ (good $X$ is the pollutant), the theoretical framework builds on those of Bhagwati, Brecher, and Hatta [12-14]; Bandyopadhay and Majumdar [15]; Bandyopadhyay and Munemo [16] and Dogbey [17].

The paper considers three cases of the pollutant and hence three models. Case one involves a situation where only consumption generates pollution (consumption is non-spatially separable). In case two only the production of good $X$ generates pollution (production is non-spatially separable). Case three involves a situation where both the production and consumption of good $X$ generates pollution (both production and consumption are non-spatially separable). The developed country is assumed to export production to the developing country even in case three. It is further assumed in case three that the developed country consumes this good hence imports the finished goods, causing it to transfer only the production emissions. The overspending (indirect utility) function of each country, $c^{i}$, is its cost (expenditure) less its revenue.

Let $q^{i}=$ the relative price of $\operatorname{good} X$.

$u^{i}=$ the welfare level of country $i$.

$P=$ the value (cost) of the pollution in terms of good $Y$.

$\delta=$ inverse distance between country $\beta$ and $\gamma ; 0 \leq \delta<1$.

$e^{i}\left(q, u^{i}\right)=$ the expenditure function of country $i$.

$r^{i}(q)=$ the revenue function of country $i$.

$x^{i}\left(q, u^{i}\right)=$ the compensated import-demand function of good $X$ by country $i ; i=\alpha, \beta, \gamma$ Then the overspending function in autarky is given by:

$$
c^{i}\left(q, u^{i}\right)=e^{i}\left(q, u^{i}\right)-r^{i}(q)^{1}
$$

During trade, the developed country's aim is to transfer pollution activities to the developing country, hence the budget equation for each country will include $P$ (the volume of trade in the pollutant), which will benefit the developed country (the exporter), but cost the developing country (importer) and the non-participant (depending on the distance between the importer and the non-participant) and hence reduce the overspending function of country $\alpha$ but increase the overspending functions of countries $\gamma$ and $\beta$. Below is the model, which comprises of the budget equations ${ }^{2}$ of the three countries and the market clearing equation of good $X$ : Thus during trade, the generic budget equation of each of the countries are:

$$
\begin{gathered}
c^{\alpha}\left(q, u^{\alpha}\right)-(1-\pi) P=0 \\
c^{\beta}\left(q, u^{\beta}\right)+\delta(1-\pi) P=0 \\
c^{\gamma}\left(q, u^{\gamma}\right)+(1-\pi) P=0
\end{gathered}
$$

where $\pi$ is any possible emission tax imposed during production. The market clearing equation is given by:

$$
c^{\alpha}\left(q, u^{\alpha}\right)+c^{\beta}\left(q, u^{\beta}\right)+c^{\gamma}\left(q, u^{\gamma}\right)=0
$$

\subsection{Case 1: Only Production Generates Pollution}

In this case, the developed country is assumed to transfer

${ }^{1}$ During trade, a country's overspending function will increase (decrease) if it is importing (exporting) good $X$.

${ }^{2}$ The budget equations are each country's overspending function during traded (adjusted for the effect of trade). 
pollution by exporting production or the pollution generating activities to the developing country, $\gamma$. It is further assumed that the developing country imposes an emission tax, $\pi(0<\pi<1)$, which reduces the amount of pollution generated in country $\gamma$ and the possible amount of pollution spillovers into country $\beta$. Unlike these two countries, since the rich country does not incur any production emission, its emission tax $\pi=0$ resulting in the following model:

$$
\begin{gathered}
c^{\alpha}\left(q, u^{\alpha}\right)-P=0 \\
c^{\beta}\left(q, u^{\beta}\right)+\delta(1-\pi) P=0 \\
c^{\gamma}\left(q, u^{\gamma}\right)+(1-\pi) P=0 \\
c^{\alpha}\left(q, u^{\alpha}\right)+c^{\beta}\left(q, u^{\beta}\right)+c^{\gamma}\left(q, u^{\gamma}\right)=0
\end{gathered}
$$

Taking total differentials of Equations (1)-(4) ${ }^{3}$ gives:

$$
\begin{gathered}
c_{u}^{\alpha} \mathrm{d} u^{\alpha}+c_{q}^{\alpha} \mathrm{d} q-\mathrm{d} P=0 \\
c_{u}^{\beta} \mathrm{d} u^{\beta}+c_{q}^{\beta} \mathrm{d} q+\delta(1-\pi) \mathrm{d} P=0 \\
c_{u}^{\gamma} \mathrm{d} u^{\gamma}+c_{q}^{\gamma} \mathrm{d} q+(1-\pi) \mathrm{d} P=0 \\
x_{u}^{\alpha} \mathrm{d} u^{\alpha}+x_{u}^{\beta} \mathrm{d} u^{\beta}+x_{u}^{\gamma} \mathrm{d} u^{\gamma}+\left(x_{q}^{\alpha}+x_{q}^{\beta}+x_{q}^{\gamma}\right) \mathrm{d} q-\mathrm{d} P=0 .
\end{gathered}
$$

Let

$$
\begin{gathered}
x_{q}=x_{q}^{\alpha}+x_{q}^{\beta}+x_{q}^{\gamma}=\sum x_{q}^{i} \\
x^{i}=c_{q}^{i} \\
c_{u}^{i}=e_{u}^{i}=\frac{\partial c^{i}}{\partial u^{i}}=1
\end{gathered}
$$

Equation (7) implies that a country will consume good $X$ until its marginal benefit of consumption equals its marginal cost or expenditure. From Equation (5) ${ }^{5}, x_{q}$ is the summation of the substitution effects, which are always negative for a normal good.

Substituting Equations (5) - (7) into the above and augmenting results in the following matrix:

$$
\left[\begin{array}{cccc}
1 & 0 & 0 & x^{\alpha} \\
0 & 1 & 0 & x^{\beta} \\
0 & 0 & 1 & x^{\gamma} \\
x_{u}^{\alpha} & x_{u}^{\beta} & x_{u}^{\gamma} & x_{q}
\end{array}\right]\left[\begin{array}{c}
\mathrm{d} u^{\alpha} \\
\mathrm{d} u^{\beta} \\
\mathrm{d} u^{\gamma} \\
\mathrm{d} q
\end{array}\right]=\left[\begin{array}{c}
1 \\
-\delta(1-\pi) \\
-(1-\pi) \\
0
\end{array}\right] \mathrm{d} P
$$

Using Cramer's rule to solve the above matrix for the welfare effects of any change in $P$ gives:

\footnotetext{
${ }^{3}$ Total differential of (1) is: $c_{u}^{\alpha} d u^{\alpha}+c_{q}^{\alpha} d q-d P=0$, and (4) is:

$x_{u}^{\alpha} d u^{\alpha}+x_{u}^{\beta} d u^{\beta}+x_{u}^{\gamma} d u^{\gamma}+\left(x_{q}^{\alpha}+x_{q}^{\beta}+x_{q}^{\gamma}+\right) d q-d P=0$.

${ }^{4}$ Shephard Lemma.

${ }^{5}$ This is the substitution effect; it's assumed that $\mathrm{X}$ and $\mathrm{Y}$ are substitutable in production and consumption.
}

$$
\begin{gathered}
\frac{\mathrm{d} u^{\alpha}}{\mathrm{d} P}=\frac{x_{q}-x_{u}^{\gamma} x^{\gamma}}{\Delta}-x_{u}^{\beta} \frac{(\pi-1)\left(\delta x^{\alpha}-1\right)}{\Delta} \\
\frac{\mathrm{d} u^{\beta}}{\mathrm{d} P}=\delta(\pi-1)\left(1+\frac{x_{u}^{\beta} x^{\beta}}{\Delta}\right)-x^{\beta} \frac{(1-\pi) x_{u}^{\gamma}+x_{u}^{\alpha}}{\Delta} \\
\frac{\mathrm{d} u^{\gamma}}{\mathrm{d} P}=(1-\pi) x^{\alpha} \frac{x_{u}^{\alpha} x^{\alpha}+x_{u}^{\beta} x^{\beta}-x_{q}}{\Delta}-\frac{(1-\pi) \delta x_{u}^{\beta} x^{\gamma}}{\Delta}
\end{gathered}
$$

where, $\Delta=-x_{q}+x_{u}^{\gamma} x^{\gamma}+x_{u}^{\beta} x^{\beta}+x_{u}^{\alpha} x^{\alpha}>0$, and $x_{q}<0$. $\Delta$ is the negative of the slope of the global excess demand function. This represents the Marshall Lerner Condition (MLC) and the Walrasian stability implies that $\Delta>$ $0 .^{6}$

From Equation (8), it is clear that if the good is Giffen, $\left(x_{u}^{\beta}<0 ; x_{u}^{\gamma}<0\right.$ and $x_{q}>0$ ) the first term on the right is positive and the second term is negative. Hence, the sufficient but not necessary condition for the developed country's enrichment is that $\delta=0$. Welfare conditions of the developed country can also alter under appropriate rankings of the developing country's marginal propensity to consume.

From Equation (9), it is apparent that the non-participant could be worse off or well off. This depends on whether or not it is a net exporter of the good and proximity to the developing country. If the distance between them is large enough $(\delta=0)$ and the non-participant is a net exporter $\left(x^{\beta}<0\right)$, the first term on the right becomes zero, and the second term on the right is positive, making

$$
\frac{\mathrm{d} u^{\beta}}{\mathrm{d} P}>0 .
$$

Thus under those conditions, the non-participant can be well off, otherwise it could be worse off.

From Equation (10), it follows that the developing country can be better off if either its net trade in the good is zero or if it is a net exporter of the good $\left(x^{\gamma} \leq 0\right)$. The first term on the right is always positive. If $x^{\gamma}=0$, the second term on the right is zero and if $x^{\gamma}<0$, the second term on the right is positive, hence

$$
\frac{\mathrm{d} u^{\gamma}}{\mathrm{d} P}>0 \text {. }
$$

Thus, the developing country is always well off.

\subsection{Case 2: Only Consumption Generates Pollution}

In this case, it is assumed that the developed country transfers pollution by exporting good $X$ to the developing

${ }^{6}$ The slope of the excess demand function is: $x_{q}-x_{u}^{\gamma} x^{\gamma}-x_{u}^{\beta} x^{\beta}-x_{u}^{\alpha} x^{\alpha}$. The MLC is thus the negative of this and it is positive. This is also proven by Bhagwati, Brecher, and Hatta [14] 
country since the consumption of the good generates pollution. Since production does not generate pollution not emission tax is imposed any of the three countries, hence $\pi=0$ for all countries involved, resulting in the following model:

$$
\begin{gathered}
c^{\alpha}\left(q, u^{\alpha}\right)-P=0 \\
c^{\beta}\left(q, u^{\beta}\right)+\delta P=0 \\
c^{\gamma}\left(q, u^{\gamma}\right)+P=0 \\
c^{\alpha}\left(q, u^{\alpha}\right)+c^{\beta}\left(q, u^{\beta}\right)+c^{\gamma}\left(q, u^{\gamma}\right)=0
\end{gathered}
$$

Taking total differentials of Equations (11)-(14) gives:

$$
\begin{gathered}
c_{u}^{\alpha} \mathrm{d} u^{\alpha}+c_{q}^{\alpha} \mathrm{d} q-\mathrm{d} P=0 \\
c_{u}^{\beta} \mathrm{d} u^{\beta}+c_{q}^{\beta} \mathrm{d} q+\delta \mathrm{d} P=0 \\
c_{u}^{\gamma} \mathrm{d} u^{\gamma}+c_{q}^{\gamma} \mathrm{d} q+\mathrm{d} P=0 \\
x_{u}^{\alpha} \mathrm{d} u^{\alpha}+x_{u}^{\beta} \mathrm{d} u^{\beta}+x_{u}^{\gamma} \mathrm{d} u^{\gamma}+\left(x_{q}^{\alpha}+x_{q}^{\beta}+x_{q}^{\gamma}\right) \mathrm{d} q-\mathrm{d} P=0 .
\end{gathered}
$$

Substituting Equations (5)-(7) into the above and augmenting results in the following matrix:

$$
\left[\begin{array}{cccc}
1 & 0 & 0 & x^{\alpha} \\
0 & 1 & 0 & x^{\beta} \\
0 & 0 & 1 & x^{\gamma} \\
x_{u}^{\alpha} & x_{u}^{\beta} & x_{u}^{\gamma} & x_{q}
\end{array}\right]\left[\begin{array}{c}
\mathrm{d} u^{\alpha} \\
\mathrm{d} u^{\beta} \\
\mathrm{d} u^{\gamma} \\
\mathrm{d} q
\end{array}\right]=\left[\begin{array}{c}
1 \\
-\delta \\
-1 \\
0
\end{array}\right] \mathrm{d} P
$$

Using Cramer's rule to solve the above matrix for the welfare effects of any change in $P$ gives:

$$
\begin{gathered}
\frac{\mathrm{d} u^{\alpha}}{\mathrm{d} P}=1+\frac{x_{u}^{\alpha} x^{\alpha}}{\Delta}-x^{\alpha} \frac{x_{u}^{\gamma}+x_{u}^{\alpha}+\delta x_{u}^{\beta}}{\Delta} \\
\frac{\mathrm{d} u^{\beta}}{\mathrm{d} P}=-\delta\left(1+\frac{x_{u}^{\beta} x^{\beta}}{\Delta}\right)-x^{\beta}\left(x_{u}^{\gamma}+x_{u}^{\alpha}\right) \\
\frac{\mathrm{d} u^{\gamma}}{\mathrm{d} P}=\frac{x^{\alpha}-x_{q}}{\Delta}+x^{\gamma} \frac{x_{u}^{\alpha}-\delta x_{u}^{\beta}}{\Delta}
\end{gathered}
$$

From (15), the developed country will always be well off. It is apparent that the second term ${ }^{9}$ on the right is less than the first term, since it is obvious that the numerator is just a fraction of the denominator.

\footnotetext{
${ }^{7}$ The budget equation of the non-participant is affected not by the full value of the pollution, but by a fraction. The longer the distance between the non-participant and its neighbor is, the smaller the value of $\delta$ is. Hence, the smaller the value of the pollution transfer or spillover is. When $\delta$ approaches zero, the non-participant's overspending function and budget equation will be same.

${ }^{8}$ By Walras Law, the market clearing equation of good $\mathrm{Y}$ is omitted.

${ }^{9}$ Note that the second term on the right of Equation (15) can be written as $x^{\alpha} \frac{d q}{d P}$, which is positive. Also, Equation (15) can be simplified as $\frac{d u^{\alpha}}{d P}=1-x^{\alpha} \frac{x_{u}^{\gamma}+\delta x_{u}^{\beta}}{\Delta}$, making it easy to prove that the second term is
} a fraction less than one.
From (16), country $\beta$ (the non-participant) could be worse off if its net trade $\left(x^{\beta}\right)$ is zero. In this case

$$
\frac{\mathrm{d} u^{\beta}}{\mathrm{d} P}=-\delta .
$$

It will however be well off if country $\beta$ and $\gamma$ are well distant apart (i.e. $\delta=0$ ) and the non-participant is a net exporter of good $\mathrm{X}\left(x^{\beta}<0\right)$. In that case the first term is zero and the second term is positive making

$$
\frac{\mathrm{d} u^{\beta}}{\mathrm{d} P}=-x^{\beta}\left(x_{u}^{\gamma}+x_{u}^{\alpha}\right)>0
$$

From (17), the developing country $(\gamma)$ is well off its distance from the non-participant is significant (i.e. $\delta=0$ ) or if its net trade in position is zero $\left(x^{\gamma}=0\right)$, or under appropriate ranking of marginal propensity to consume. The first term on the right of Equation (17) is positive, and provided any of the three conditions above, the second term is also positive, making

$$
\frac{\mathrm{d} u^{\gamma}}{\mathrm{d} P}>0
$$

On the other hand, the developing country $(\gamma)$ could be worse off if, for example, the good is Giffen $\left(x_{q}>0\right)$ and thus an inferior good $\left(x_{u}^{\alpha}<0\right)^{10}$.

\subsection{Case 3: Both Consumption and Production Generate Pollution}

This is the case where production and consumption of the pollutant are non-spatially separable. In this case, the developed country still shifts production to the developing country but imports the good for consumption and hence reduces the total amount of pollution it would have consumed. Since there is no production emission for the developed country, its emission tax, $\pi=0$. However, since consumption generates pollution the developed country's (and the other countries') overspending function increases by $P^{11}$. The other two countries would incur both a production pollution $((1-\pi) P)$ and consumption pollution $(P)$, resulting in the following budget equations:

$$
\begin{gathered}
c^{\alpha}\left(q, u^{\alpha}\right)+P=0 \\
c^{\beta}\left(q, u^{\beta}\right)+\delta(2-\pi) P=0 \\
c^{\gamma}\left(q, u^{\gamma}\right)+(2-\pi) P=0
\end{gathered}
$$

\footnotetext{
${ }^{10}$ The Marginal Propensity to Consume is given by $x_{u}^{i} / e_{u}^{i}=x_{u}^{i}$, since $e_{u}^{i}=1$ from Equation (7).

${ }^{11}$ The develop country overspending function (net cost) increases by the consumption pollution $(\mathrm{P})$, since it is now importing the pollutant like the other two countries in the first two cases.

${ }^{12}$ Since the developing country's production of the pollutant will be affected by the emission tax but consumption not affected by the tax, its budget equation is $c^{\gamma}\left(q, u^{\gamma}\right)+[(1-\pi) P+P]=0$, which simplifies to Equation (20) above.
} 


$$
c^{\alpha}\left(q, u^{\alpha}\right)+c^{\beta}\left(q, u^{\beta}\right)+c^{\gamma}\left(q, u^{\gamma}\right)=0
$$

The market clearing equation remains the same as in case 1 and case 2 above. Using the same conditions and assumptions as above and totally differentiating, gives:

$$
\begin{gathered}
c_{u}^{\alpha} \mathrm{d} u^{\alpha}+c_{q}^{\alpha} \mathrm{d} q+\mathrm{d} P=0 \\
c_{u}^{\beta} \mathrm{d} u^{\beta}+c_{q}^{\beta} \mathrm{d} q+\delta(2-\pi) \mathrm{d} P=0 \\
c_{u}^{\gamma} \mathrm{d} u^{\gamma}+c_{q}^{\gamma} \mathrm{d} q+(2-\pi) \mathrm{d} P=0 \\
x_{u}^{\alpha} \mathrm{d} u^{\alpha}+x_{u}^{\beta} \mathrm{d} u^{\beta}+x_{u}^{\gamma} \mathrm{d} u^{\gamma}+\left(x_{q}\right) \mathrm{d} q-\mathrm{d} P=0 .
\end{gathered}
$$

Substituting Equations (6) and (7) into the above and augmenting results in the following matrix:

$$
\left[\begin{array}{cccc}
1 & 0 & 0 & x^{\alpha} \\
0 & 1 & 0 & x^{\beta} \\
0 & 0 & 1 & x^{\gamma} \\
x_{u}^{\alpha} & x_{u}^{\beta} & x_{u}^{\gamma} & x_{q}
\end{array}\right]\left[\begin{array}{c}
\mathrm{d} u^{\alpha} \\
\mathrm{d} u^{\beta} \\
\mathrm{d} u^{\gamma} \\
\mathrm{d} q
\end{array}\right]=\left[\begin{array}{c}
-1 \\
-\delta(2-\pi) \\
-(2-\pi) \\
0
\end{array}\right] \mathrm{d} P
$$

Using Cramer's rule to solve the above matrix for the welfare effects of any change in $P$ gives:

$$
\begin{aligned}
& \frac{\mathrm{d} u^{\alpha}}{\mathrm{d} P}=\frac{\left(x^{\beta}-x^{\gamma}\right)\left[x_{u}^{\beta}+(2-\pi) x^{\alpha}\right]}{\Delta}-\frac{x_{u}^{\gamma} x^{\gamma}+\delta x^{\alpha} x_{u}^{\beta}-x_{q}}{\Delta} \\
& \frac{\mathrm{d} u^{\beta}}{\mathrm{d} P}=(\pi-2) \frac{(\delta-1)\left(x_{q}-x_{u}^{\alpha} x^{\alpha}\right)-\delta x^{\beta} x_{u}^{\gamma}}{\Delta}+x_{u}^{\alpha} \frac{x^{\beta}-x^{\gamma}}{\Delta} \\
& \frac{\mathrm{d} u^{\gamma}}{\mathrm{d} P}=(\pi-2) \frac{x_{q}-x_{u}^{\alpha} x^{\alpha}-\delta x^{\beta} x_{u}^{\gamma}}{\Delta}+\frac{(\pi-2) x_{u}^{\beta}}{\Delta}-\frac{x_{u}^{\alpha} x^{\gamma}}{\Delta}
\end{aligned}
$$

From Equation (22), it is obvious that if the developing country's net trade position is zero $\left(x^{\gamma}=0\right)$, and if $\delta$ $=0$, the first term on the right is positive and the second term becomes

$$
\frac{x_{q}}{\Delta},
$$

which is negative. If this second term is less than the first term or if the good is Giffen (in which case the substitution effect, $x_{q}$, is positive) then the developed country can be better off. Otherwise, it could be worse off.

Similarly, Equation (23) shows that the non-participant could be better off in many cases. For example if the net trade positions of both the developed and the developing country are zero $\left(x^{\alpha}=x^{\gamma}=0\right)$ and if the if the distance between the non-participant and the developing country is significant $(\delta=0)$, then

$$
\frac{\mathrm{d} u^{\beta}}{\mathrm{d} P}=-(\pi-2) \frac{x_{q}}{\Delta}+x_{u}^{\alpha} \frac{x^{\beta}}{\Delta}>0 .
$$

Assume without loss of generality that the developing country and the non-participant are well distant apart (i.e. $\delta=0$ ), then the first term on the right of Equation (23) is positive. If the developing country is a net exporter of the good or if its net trade position is zero $\left(x^{\gamma} \leq 0\right)$, the second term is positive. Under the conditions stated above,

$$
\frac{\mathrm{d} u^{\gamma}}{\mathrm{d} P}>0 \text {. }
$$

Thus, the developing country will be well off.

\section{Comparing Welfare Effects for All Cases}

This section summarizes each comparative static analysis for all cases to see if welfare effects differ significantly from case to case. This helps identify under what conditions economic agents (countries) are well off or worse off when countries engage in trade involving a pollutant. Below are the other comparative analyses for each country in the model.

The developed country's welfare effects are as follows: if the pollutant is non- spatially separable in consumption, the developed country is always better off. This could be due to the favorable terms of trade arising from the increase in the relative price of the good. If the good is non-spatially separable in production only, the developed country can be well off if the pollutant is Giffen, making the substitution effect positive, and if the distance between the developing country and its neighbor is sufficiently large or under appropriate rankings of the developing country's marginal propensity to consume. If the good is non-spatially separable in both consumption and production, the developed country will only be well off if the developing country's net trade is zero, the good is Giffen and the distance between non-participant and the developing country is large.

The developing country's welfare effects during trade in a pollutant are summarized below. In the case where the good is non-spatially separable in consumption only, the developing country could be well off unless the good is Giffen (and hence inferior). In the case where only production is non-spatially separable, the developing country could always be well off. This holds strongly especially if either its net trade in the good is zero, or if it is a net exporter of the good, or if its distance from the non-participant is sufficiently large. Finally, in the case where both the consumption and production are nonspatially separable the developing country could still have possibilities of welfare gains. This could happen if the developing country is a net exporter of the good and the distance between the developing country and the nonparticipant is sufficiently large (to avoid any possible emission spillovers from the non-participant).

The non-participant also stands to benefit or lose when 
neighboring countries trade in the pollutant. These effects arise from the relative price of the good and distance from the developing country. In the case where only the consumption of the good is non-spatially separable, the non-participant could be worse off if its net trade in the good is zero. Since the relative price of the good increases in this case, having a zero net trade position will not auger favorably for this country's terms of trade. Alternatively, it will be better off if it is a net exporter of the good (the increase in relative price of the good favoring its terms of trade), or if its distance from the developing country is sufficiently large (eliminating pollution spillovers). This same condition for the nonparticipant's enrichment stated above holds for the case where only production is non-spatially separable. For the case where both the consumption and production of the pollutant are non-spatially separable, the non-participant could be well off. For example, if the net trade position of both the developing country and the developed country is zero and if the net trade position from the developing country is sufficiently large in order to avoid any pollution spillovers.

\section{Conclusions}

This paper investigates the welfare effects of bilateral trade involving a pollutant in a multilateral context. It seeks to find out the types of pollutant and the conditions under which they either worsen or improve the trade partners' welfares as well as their neighbors who are not partners in trade. The results of this paper suggest that increase trade in goods that generate pollution in production, or consumption or in both production and consumption does not always reduce countries' welfare but can also increase global welfare under certain conditions.

The paper finds that for all cases including the pollutant being spatially separable in production or consumption (i.e. only consumption or only production or both generates pollution), there could be welfare gains or losses for the developed country and the developing country as well as the non-participant. Factors that could increase or decrease the gains or losses include the possibility of substitutability in both consumption and production of the pollutant, countries' marginal propensity to consume as well as their trade positions as net exporters and net importers of the pollutant. Finally, the extent to which a country imposes emission tax on production could also determine whether welfare gains could increase or decrease.

In all the cases, the paper finds evidence of welfare gains for all the economic agents involved. The paper also makes the case that specialization during trade can lead to efficient levels of pollution emission during production and hence as with welfare ramifications. The policy recommendation of the paper is that for those pollutants, which are necessities and yet are spatially non-separable in production and or consumption, there could still be welfare gains when countries open up for trade whether developed or developing. Since these goods would be produced anyway, opening up for trade under certain conditions as suggested above could improve countries' welfare as well as global welfare.

\section{REFERENCES}

[1] G. Grossman and A. Krueger, "Environmental Impacts of a North American Free Trade Agreement,” NBER Working Paper Series, 1991.

[2] G. Grossman and A. Krueger, "Economic Growth and the Environment,” The Quarterly Journal of Economics, Vol. 112, No. 3, 1995, pp. 353-377.

http://dx.doi.org/10.2307/2118443

[3] H. X. Huang and W. Labys, "Modeling Trade and Environmental Linkages in China," International Journal of GlobalIssues, Vol. 4, No. 4, 2004, pp. 242-266.

[4] K. E. McConnell, "Income and the Demand for Environmental Quality," Environment and Development Economics, Vol. 2, No. 4, 1997, pp. 383-399. http://dx.doi.org/10.1017/S1355770X9700020X

[5] N.Khanna, "The Income Elasticity of Non-point Source Air Pollutants: Revisiting the Environmental Kutznets Curve,” Economic Letters, Vol. 77, No. 3, 2002, pp. 387392. http://dx.doi.org/10.1016/S0165-1765(02)00153-2

[6] N. Khanna and F. Plassmann, "The Demand for Environmental Quality and the Environmental Kuznets Curve Hypothesis,” Ecological Economics, Vol. 51, No. 3-4, 2004, pp. 225-236. http://dx.doi.org/10.1016/j.ecolecon.2004.06.005

[7] M. Das and S. K. Das, "Trade, Environment, and Welfare in a Model of Monopolistic Competition,” Eastern Economic Journal, Vol. 38, No. 1, 2012, pp. 37-56. http://dx.doi.org/10.1057/eej.2010.50

[8] G. Heal, "Discounting: A Review of the Basic Economics," The University of Chicago Law Review, Vol. 74, No. 1, 2007, pp. 59-77

[9] M. L. Weitzman, "Why the Far-Distant Future Should Be Discounted at Its Lowest Possible Rate," Journal of Environmental Economics and Management, Vol. 36, No. 3, 1998, pp. 201-208. http://dx.doi.org/10.1057/eej.2010.50

[10] B. R. Copeland and S. M. Taylor, "International Trade and the Environment: A Framework for Analysis,” NBER Working Papers 8540, National Bureaux of Economic Research, Inc., Cambridge, 2001.

[11] B. R. Copeland and S. M. Taylor, "North-South Trade and the Environment," The Quarterly Journal of Economics, Vol. 109, No. 3, 1994, pp. 755-787. http://dx.doi.org/10.2307/2118421

[12] J. Bhagwati, R. Brecher and T. Hatta, “The General Theory of Transfers and Welfare: Bilateral Transfers in a Multilateral World,” American Economic Review, Vol. 73, No. 4, 1983, pp. 606-618.

[13] J. Bhagwati, R. Brecher and T. Hatta, "Foreign Owner- 
ship and the Theory of Trade and Welfare,” Journal of Political Economy, Vol. 89, No. 3, 1981, pp. 497-511. http://dx.doi.org/10.1086/260982

[14] J. Bhagwati and R. Brecher, "Immiserizing Transfers from Abroad," Journal of International Economics, Vol. 13, No. 3-4, 1982, pp. 353-364.

http://dx.doi.org/10.1016/0022-1996(82)90063-0

[15] S. Bandyopadhyay and B. Majumdar, "Multilateral Transfers, Export Taxation and Asymmetry," Journal of Development Economics, Vol. 73, No. 2, 2004, pp. 715-725. http://dx.doi.org/10.1016/j.jdeveco.2003.05.001

[16] S. Bandyopadhyay and J. Munemo, “Transfers, Trade, Taxes and Endogenous Capital Flows: With Evidence from Sub-Saharan Africa,” International Journal of Business and Economics, Vol. 5, No. 1, 2006, pp. 29-40.

[17] J. Dogbey, "Global Relative Prices in the Face of a Pollution Transfer Problem," Theoretical Economics Letters, Vol. 2 No. 5, 2012, pp. 557-560.

http://dx.doi.org/10.4236/tel.2012.25102 